\title{
Lo que se bailó en Costa Rica Actividad dancística ejecutada en los teatros capitalinos de Costa Rica durante el año 2015
}

\author{
Marta Ávila Aguilar
}

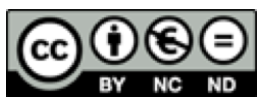

Esta obra está bajo una licencia Creative Commons Reconocimiento- No comercial-Sin Obra Derivada 

Reflexiones

\title{
Lo que se bailó en Costa Rica Actividad dancística ejecutada en los teatros capitalinos de Costa Rica durante el año 2015
}

\author{
Marta Ávila Aguilar ${ }^{1}$ \\ Escuela de Danza. Universidad Nacional \\ mavila@una.cr
}

Recibido: 16 de enero del 2016 Aprobado:18 de febrero de 2016

\section{Resumen}

Este texto pretende, como resumen, dar una idea de cuál fue la principal actividad dancística de creadores nacionales y extranjeros que se ejecutó en los teatros capitalinos de Costa Rica durante el 2015.

Palabras clave: danza escénica, danza moderna, danza contemporánea, ballet, coreógrafos de América Central

\begin{abstract}
As a summary, this work pretends to show the principal dance activities produced by national and foreign coreographers performed in the principal theaters of Costa Rica in 2015.
\end{abstract}

Keywords: scenic dance, modern dance, contemporary dance, ballet, Central American choreographers.

\footnotetext{
${ }^{1}$ Doctora en Cultura Centroamericana por la Universidad Nacional; Master en Artes y Licenciada en Historia de Arte por la Universidad de Costa Rica. Catedrática de la Escuela de Danza de la UNA, académica e investigadora en su especialidad. Bailarina, coreógrafa y miembro fundador de la Compañía de Danza Universitaria
} 


\section{Reflexiones}

En 2015, el gremio dancístico costarricense aprovechó los festivales nacionales para promover sus coreografías de repertorio y de estreno. De igual forma, muchas agrupaciones independientes, y algunos solistas, retomaron la labor de extensión en zonas fuera del área metropolitana para mostrar sus obras.

\section{Lo general}

La actividad de danza contemporánea y ballet clásico, en Costa Rica, durante el año 2015, se caracterizó por una baja intensidad por parte de las tres compañías estatales, las cuales realizaron temporadas de repertorio y estreno; además, hubo pocos espectáculos internacionales; se realizaron los festivales nacionales con alguna que otra novedad y el sector independiente mermó su producción coreográfica.

Como punto importante de lo visto y bailado en este año, es posble señalar la fuerte participación de intérpretes masculinos, tanto en la creación coreográfica como en la ejecución, con buena técnica y expresividad. Por lo visto, en los principales escenarios metropolitanos, se puede señalar que ya casi igualan en número a las mujeres, sector que predominó en el pasado. Esto sucede solamente en la danza contemporánea, porque en el ballet todavía no hay tantos profesionales masculinos que se dediquen a este tipo de montajes con el nivel de excelencia. Por su parte, los montajes como Cascanueces, siguen necesitando de figuras internacionales.

\section{Lección inaugural universitaria desde la danza}

Un hecho inédito que se dio en 2015 fue la decisión del rector de la Universidad de Costa Rica, Henning Jensen Pennington, de invitar al maestro, bailarín y coreógrafo colombiano, Álvaro Restrepo, para la celebración de los 75 años de labor académica de la Universidad, a impartir la lección inaugural. Es importante recordar que estas actividades siempre han privilegiado la participación de científicos o intelectuales de otras áreas del conocimiento y fue hasta el año 2015 que la comunidad dancística costarricense pudo acudir en pleno a escuchar la disertación y observar los movimientos que el maestro colombiano Restrepo preparó para compartir con sus colegas y el público en general. Sus palabras se derivaron de su experiencia internacional y los logros pedagógicos en $\mathrm{El} \mathrm{Co-}$ legio del Cuerpo, institución creada en 1997 -junto con la bailarina francesa Marie France Delieuvin- la cual, él ahora dirige en Bogotá.

\section{Festival de Butoh}

La actividad dancística inició temprano, debido a que el bailarín y coreógrafo Fred Herrera, ideó y logró financiar con recursos de Proartes, un Festival de Butoh que se desarrolló entre los meses enero y mayo, el cual permitió al público y bailarines participar en muchas actividades como talleres, conversatorios y presentaciones en varios escenarios nacionales. Entre ellas, se observaron obras de creadores que cultivan esta tendencia 
creativa, dentro de los cuales destacó el japonés Tadashi Endo, quien ejecutó de manera magistral Fukushima Mon Amour. También resaltaron autores como las mexicanas Lola Lince, Esparta Martínez, el español Javier Ciria y la brasileña Rosana Barra, así como Anzar Danza Experimental y el mismo Herrera, quien presentó cuatro espectáculos: Descenso al infierno, Gigante de sal, Los ladrones de la perla y Paraíso; todas estas creaciones estuvieron enmarcadas dentro de la estética que plantea la danza Butoh.

\section{Labor ordinaria}

La Compañía de Cámara Danza UNA, dirigida por Nandayure Harley, participó en varios festivales. Esta dio su temporada de repertorio denominado Septo, en Heredia, en la que se mostraron obras de sus jóvenes integrantes como Beta bulgaris de Kimberly Ulate, Re de Melissa Montero, Paloma de Yul Gatjents, Brío, creada en conjunto por Adriana Villalobos y Mariela Arguello; igualmente, se bailó Inna mi Jaad de Karlton Lacey. Con los mencionados espectáculos, se logró demostrar que en la variedad está el gusto

De igual forma, esta agrupación participó en el estreno de la producción interdisciplinaria Canto fúnebre, en la que se mostraron tradiciones desconocidas que valoran los ritos, algunos como un festín de viaje a lo desconocido. Dicha obra fue ejecutada en las inmediaciones del Museo de Jade en San José y en el Centro Cívico Omar Dengo en Heredia. La compañía de Cámara Danza UNA se mantuvo muy activa realizando varias funciones de extensión fuera del Valle Central. Por otra parte, debe destacarse que la obra Paloma, de Yul Gajents, obtuvo el reconocimiento de los Premios Nacionales que otorga el Ministerio de Cultura como mejor coreografía del año.

De esa misma institución universitaria, resalta la agrupación UNA Danza Joven, coordinada por Valentina Marenco y Fito Guevara, la cual es un espacio académico que les permite crecer en el escenario a través de muchas funciones de extensión con obras del repertorio como Jaguar de Mario Blanco; además, esta organizó el estrenó Ego Ritus de la coreógrafa invitada Estefanía Dondi en el Teatro de la Danza, en la que predominó la fuerza del colectivo.

De igual modo, en la Universidad de Costa Rica, Danza Universitaria, bajo la dirección de Hazel González, remontó la obra de Gloriana Retana La trampa y Reconstrucción de Mario López y Pablo Miranda; esta compañía realizó actividades de extensión en varias comunidades. El estreno del año fue la coreografía Inercia de Gustavo Vargas, un trabajo de corte abstracto que estimula la imaginación a través de movimientos vertiginosos. Todas estas ejecuciones se dieron en Teatro de Montes de Oca y en en el Teatro de la Danza.

Por otra parte, el programa de formación dancística Danza Abierta, dirigido por Luis Piedra, se concentró en el estreno Regresión, un montaje de Pepe Hevia con los jóvenes bailarines que obtuvo muy buenos resultados 


\section{Reflexiones}

tanto a nivel estético como en la interpretación, en la cual el cuerpo fue el principal instrumento. Este grupo realizó otra temporada con obras de miembros de la institución; Iván Saballos, Evelyn Ureña y Garry Rosales quienes crearon Logos y, en ese programa, invitaron al bailarín de la Compañía Nacional de Danza Javier Jiménez, quien montó Que le corten la cabeza. Además, Luis Piedra remontó su creación Des-Hechos.

La Compañía Nacional de Danza (CND) organizó la novena edición de Mudanzas y presentó tres temporadas de estreno: la primera denominada Coreógrafos residentes, en la que participaron Alexander Solano con la obra grupal, La pared del fondo, Mario Vircha con Formula sensible y el solo de Laura Murillo titulado Piscis. Luego, el elenco oficial bailó la obra de la coreógrafa independiente Ana María Moreno, espectáculo dirigido para un público juvenil titulado Too, toc, toc... una mirada al revés, en donde los bailarines danzaron como si estuvieran jugando; dicha obra obtuvo el premio como mejor producción. A final del año, el grupo oficial interpretó de su director, Adrián Figueroa, Taciturno, con muy buenos resultados compositivos e interpretativos, gracias a su capacidad de síntesis y sentido de grupo logrado por los bailarines.

\section{Los destacados}

Según nuestro criterio -y más allá de los reconocimientos oficiales- consideramos que, como bailarinas, Laura Murillo y Melissa
Rivera fueron las mejores intérpretes, ya que cada una, por su lado y posteriormente en conjunto, demostraron que están en su mejor momento escénico. De igual forma, destacaron por sus actuaciones en varios trabajos Heriberto Calderón, Javier Jiménez y Karlton Lacy. A nivel compositivo Taciturno de Adrián Figueroa, a mi consideración, fue la coreografía que mejor resultados escénicos tuvo, tanto en el tratamiento del tema como en el tratamiento interpretativo, conceptual y estético.

\section{Los festivales}

De los seis festivales que se realizaron en 2015 (Festival Nacional de Danza, Festival de Coreógrafos Graciela Moreno, Festival Callejero La Machine, SolodosenDanza, Movimientos desplegados y A puro cuerpo) cinco permitieron ver propuestas internacionales, siendo la excepción el Festival de Coreógrafos. Un ejemplo de lo anterior, es la participación de la coreógrafa española Carmen Werner, de quien se logró presenciar dos obras: la primera, en el Festival Callejero La Machine, en marzo, y la otra en el Festival Movimientos Desplegados. Destaco que el Festival Callejero La Machine se realizó por segunda vez, con participación de obras creadas por bailarines nacionales y extranjeros, las cuales se danzaron al aire libre, conviertiéndose así en un espacio que permitió actualizar lecturas de los discursos coreográficos.

El Festival Nacional de Danza en su XIV Edición, apoyado por el Teatro Melico Salazar, se realizó durante nueve días y fue 
aprovechado tanto por las agrupaciones institucionales como independientes para mostrar de nuevo sus montajes; este contó con dos invitados internacionales: la española Victoria Pérez Miranda y la Compañía de Danza de República Dominicana. Sin embargo, en este encuentro sería pertinente que cada año se baile una creación, bien seleccionada, de décadas anteriores, con el fin de recuperar y valorar el repertorio nacional.

Del mencionado festival, uno de los trabajos que resultó muy interesante fue la propuesta titulada Guara ar iu filin?, del coreógrafo costarricense - radicado en Santo Domingo- Francisco Centeno, ejecutada por el elenco de la Compañía Nacional de Danza de República Dominicana y en la cual fue evidente el trabajo de buen nivel técnico ejecutado por cuerpos poderosos e imágenes irreverentes.

Por su parte, el Festival de Coreógrafos Graciela Moreno sigue siendo un espacio vital para el desarrollo de la disciplina; también, es el más esperado, controversial y criticado, por el mismo sector, ya que los creadores pueden ver sus obras en las mejores condiciones técnicas y con buen público. En esta edición, se programaron quince creadores nacionales en las que predominó el uso de la voz como si el movimiento no les fuera suficiente para plantear su discurso escénico. Al final, quedó un sin sabor, porque dos categorías no se premiaron. En este sentido, cabe la pregunta si será ese el objetivo principal de participar en el espacio que lleva XXXII ediciones. Tal vez, a modo de reflexión, sea preferible que se preparen mejor y participen más creadores para que “continúe el espectáculo".

Dirigido por Vicky Cortés, el Festival Movimientos Desplegados reunió a varias intérpretes: Martha Rosvel y Violeta Luna de México, la española Carmen Werner, Paola Lorenzana de El Salvador, Cristina Moura de Brasil y las costarricenses Elia Arce y la mencionada Vicky Cortés, quienes se presentaron en Gráfica Génesis y otros espacios alternativos; este fue un evento en el que se pudieron observar interesantes propuestas de solistas femeninas, sin embargo, contó con poco público.

En el Festival SóLODOS en Danza que se realizó en la ciudad de Barva, en Heredia, por tercer año consecutivo, Maruxa Salas y Erick Jiménez lograron reunir a doce autores y bailarines de diferentes países, con un jurado internacional, que permite a los ganadores insertarse y participar en plataformas de danza contemporánea en España y México.

Finalmente, Gráfica Génesis también albergó la segunda edición del festival de danza contemporánea A puro cuerpo, con mejoras como talleres de movimiento, escritura, conversatorios y funciones. Además, tuvo la participación de la crítica de danza uruguaya Lucía Nassar, quien desarrolló un taller de escritura danzaria durante este evento. Esta es una estrategia del gremio para unirse en una muestra que permita ver trabajos de colegas centroamericanos. 


\section{Reflexiones}

\section{Espacios para danzar}

La Galería Gráfica Génesis, dirigida por Ricardo Alfieri y Adrián Figueroa, en 2015, se convirtió en la principal sala de danza de nuestro país, pues en ella se realizó la mayor cantidad de espectáculos. Por su parte, el segundo escenario en importancia por albergar espectáculos fue el Teatro de la Danza y, finalmente, el Teatro Montes de Oca. En este sentido, es importante destacar que Gráfica Génesis patrocina varios festivales, iniciativas emergentes, temporadas temáticas y muestras experimentales; es decir, casi se ha convertido en la casa de la danza independiente. Por ejemplo, en este espacio, en 2015, se realizaron las temporadas denominadas Verano de independientes en la que jóvenes creadores como Yul Gatjens, Sofía Solís, Kimberly Ulate, Lourdes Venegas, Mónica Sánchez e Irene Araya bailaron sus creaciones. Posteriormente, vino Muestra Experimental Independiente (MEI) que agrupó la producción de ocho jóvenes creadores, la cual resultó ser un acto de solidaridad escénica con un menú diverso.

También, en esta sala, fue posible observar el espectáculo Beauty de Yul Gajents, cuya temática principal consistió en mostrar la tragedia de la belleza exterior y pobreza interior de las personas. Asimismo, se presentaron las reposiciones Cúbico, creado por Ana Paola Rivera, el cual fue ejecutado por la autora -junto con Gabriel Rodríguez y Ana Cristina Rojas- y Bastarda tabacalera, de Jorge Sánchez, obra que va del goce escénico a la denuncia y plantea el tema de la diversidad sexual con mucho humor; de igual manera, el unipersonal de Francisco Centeno Homotexual, ejecutado por Adrián Figueroa. El Teatro Las afueras, dirigido por Alex Catona y Andrea Catania, también ocupó esta sala para mostrar su último trabajo.

No obstante, es fundamental indicar que, la imposibilidad para muchos miembros de las agrupaciones oficiales o de grupos independientes de bailar en teatros o escenarios de mayor dimensión, podría ser la causa de que una generación de bailarines crezca sin la oportunidad de enfrentarse al reto de bailar en un escenario de grandes dimensiones, el cual requiere mayor proyección expresiva. Esto, ya que -sin tomar encuenta el espacio que ofrecen los distintos festivales- ningún grupo nacional tuvo su temporada en el Teatro Melico Salazar o en el Teatro Nacional. La pregunta es ¿por qué ya no se puede bailar en estas salas?, y, por tanto, ¿cómo van a crecer los intérpretes, así como lo hacen los músicos de las orquestas nacionales? Este es un tema para pensar y formular políticas de apoyo al sector.

\section{En solitario}

Algunas bailarinas creadoras decidieron presentarse solas, como fue el caso de Erika Mata, quien ejecutó la creación Transmutaciones compartidas al ocaso de un solsticio en el Teatro Atahualpa del Cioppo, en Heredia. De igual modo, lo hizo Milena Picado en el Teatro Expresivo, al ejecutar el espectáculo de corte flamenco Fragmentos. 


\section{Otros estrenos}

En el Teatro de la Danza, a inicio del año anterior, los bailarines y coreógrafos Maruxa Salas y Erick Jiménez bailaron el dúo inspirado en las costumbres, lugares y sabores de cada una de sus culturas (España y Costa Rica) en una coreografía llena de rupturas corporales denominada Sazón. Para el segundo semestre, Fito Guevara dirigió a las bailarinas Wendy Chinchilla, Melissa Rivera, Andrea Núñez y a la actriz Ana Taína Aguilar, en una propuesta de investigación interdisciplinaria titulada Formulas femeninas en la cual abordaron aspectos del imaginario de la mujer con ricos juegos corpóreos en los que se combina la palabra y el movimiento.

El Teatro Montes de Oca, como escenario de varios estrenos, permitió apreciar el espectáculo denominado Quark pedacitos de todo, creado por Metzi Hovenga. En este espacio, de igual forma, se presentó Dominó, una producción con miembros de la nueva agrupación que dirige Rogelio López, con una duración de más de dos horas en las que trató sus temas recurrentes como son los afectos en las relaciones interpersonales y la exclusión social de la mujer, en la cual los bailarines hablaron sin palabras gracias al poder del movimiento bien articulado.

El grupo independiente Exánima presentó un trabajo inspirado en el texto mitológico maya titulado Xibalbá creado por Ana María Moreno y Erick Cascante. Por su parte, Danza Abend bailó en el espacio Teatro al Medio Día del Teatro Nacional, las obras del repertorio de su creadora Cristina Gigirey:
La casa de Bernarda Alba, Proceso y Aproximaciones, presentaciones que gozaron de buena acogida por parte del público. El grupo Andanza, dirigido por Lorenlayne Varela, de Cartago, por primera vez realizó dos temporadas en San José con distintos espectáculos en los cuales se invitó a los coreógrafos Pablo Caravaca, Mario Vircha y Javier Jiménez; con dichas temporadas, estos artistas demuestran que van a paso firme.

Cabe destacar que el joven creador y bailarín Javier Jiménez, durante todo el año, estuvo muy activo y logró presentar cinco obras con varias agrupaciones como la CND, Andanza, Danza Abierta y en el Festival de Coreógrafos: En algún lugar, Inevitable, Vidas sedientas, Que le corten la cabeza y Partes iguales. El grupo independiente Inquieta Res presentó Fun with knives. Finalmente, en el Teatro Melico Salazar se presentó, con buena aceptación del público, el musical West Side Story, con coreografía de María Amalia Pendones.

\section{El ballet en Costa Rica}

El Cascanueces, dirigido por Patricia Carreras y María Amalia Pendones, sigue siendo la producción que aglutina a todo el sector interesado en la danza clásica, en donde el público lo respalda con llenar la sala durante una larga temporada; este año, nuevas protagonistas nacionales asumieron los papeles principales al lado de solistas internacionales. Dicho laboratorio del ballet presentó algunos cambios en la composición coreográfica. También, la agrupación Danzay, dirigida 


\section{Reflexiones}

por Maria Amalia Pendones celebró sus tres lustros de trabajo escénico con la reposición del ballet La Sirenita. Además, la Academia Superior de Ballet Clásico montó, con Margaret Mahuys, una versión del ballet Copelia.

Desde el exterior pudimos ver el Russian Clasical Ballet cuyos integrantes desarrollaron el ballet completo Romeo y Julieta con excelentes resultados al ejecutar temas universales y pasiones eternas. De igual modo, a inicio de año, el público costarricense pudo ver Corteo, otro espectáculo del Circo del Sol.

\section{Pérdidas sentidas}

En nuestro país, dos personas importantes dejan un vacío en el gremio dancístico: el maestro, bailarín y coreógrafo Julián Calderón de 85 años de edad, así como la colombiana bailarina, coreógrafa y gestora artística Ofír León, de 40 años. En el panorama mundial se sintió mucho la muerte de Maya Plisétskaya, con quien, a sus 89 años, se cierra la era de la potencia soviética en el ballet, pues esta bailarina después de Anna Pavlova, encantó por la ejecución de La muerte de cisne de Michel Fokine, obra emblemática del ballet de principios del siglo XX. 